\title{
Freund's Complete Adjuvant (FCA) Could Reverse the Depressive-Like Symptoms Induced by Chronic Mild Stress (CMS) in Mice
}

Hacene Frih $^{1 *}$, Lamia Bensaci', Redha Djenidi', Bachir Ali Rachedi', Tahraoui Abdelkrim and Sylvain Fisson ${ }^{2}$

${ }^{1}$ Faculté des Sciences, Département de Biologie, Laboratory of Applied Neuro-Endocrinology, Université Badji Mokhtar Annaba, Algeria

2GENETHON, Unité INSERM UMRS 951, “Gene Transfer and Immune Sanctuaries” Group, Université d'Evry Val d'Essonne (UEVE), 1 bis rue de I'Internationale, F-91002, EVRY, France

\begin{abstract}
Background: The objective of this work was a comparative study of two animal models in female mice: Chronic Mild Stress (CMS) and Chronic Mild Stress combined with chronic inflammation with complete Freund's adjuvant (CMS+CFA).

Methods: Mice were exposed to CMS for 40 days as food deprivation, water deprivation, forced swimming, flashing light, isolation, wet bedding and wet litter at $4^{\circ} \mathrm{C}$. The stress was applied at times that change every day, in order to minimize its predictability. A subcutaneous injection of $0.03 \mathrm{mg} / \mathrm{ml}$ of CFA was administered to CMS groups the $18^{\text {th }}$ day of experimentation. Recordings of sequences of behavior in elevated plus maze, open field test and water maze test was made. After decapitation, the brain, thymus, spleen, liver, kidneys, adrenals and ovaries were weighed and we calculated their relative weights.
\end{abstract}

Results: Exposure of mice to CMS caused a depraessive-like behavior revealed by behavioral tests, accompanied by a decreased gain of body weight, locomotor activity and impaired spatial memory signaled by the Morris water maze test. The injection of CFA in mice submitted to a CMS has provided a partial repair of the memory in the Morris water maze, locomotor activity, gain of body weight, weight of adrenals.

Conclusion: Freund's complete adjuvant (FCA) could reverse the depressive-like symptoms induced by chronic mild stress (CMS) in mice.

Keywords: CMS; CFA; Inflammatory; Neuroprotection; Memory; Anxiety; Depression

\section{Introduction}

The last decade intricate relationship between inflammation and depression has attracted increasing attention in all areas of research due to its multiple applications. Previous studies indicate that neuroinflammation and depression share common neuroanatomical pathways and neurobiological substrates, which might explain the increased vulnerability to neuroinflammation in depressive patients and vice versa [1]. The correlation between depression and neuroinflammation is still a matter of debate and has not been fully understood.

Like stressful life events, external stressors and/or internal stressors such inflammatory conditions are widely acknowledged as a predisposing and precipitating factor of depression and consequently are involved in the etiology of depression [2-7].

The chronic mild stress (CMS) animal model is one of the classical depression models introduced by Willner et al. [8]. The paradigm consists of several mild stressors which are analogous to those associated with humans. In this paradigm, animals are subjected to a variety of mild stressors every day. After several weeks, the animals show a decrease in consumption of a palatable sweet solution, known as anhedonia, which is the core character of depression [9].

Otherwise, in animals and humans, systemic inflammatory pathways provoke sickness behavior, including behaviors such as anhedonia, reduction of locomotor activity, exploration and grooming, lethargy, anxiety, sleepiness, anorexia, weight loss, hyperalgesia and failure to concentrate or memory disturbances [10-16].

The inflammation induced by Freund's adjuvant is considered as a model for T-cell dependent, autoimmune diseases and the central symptoms constitute the sickness behavior, namely behavioral changes that follow immune response [17]. One of the characteristics of unhealthy behavior obtained experimentally in recent studies was the change in circadian release rhythm of several hormones occurring 18 days after injection of complete Freund's adjuvant in mice.

The aim of our study was to explore behavioral reactivity to various paradigms (evolution of weight, locomotor activity in the Open field, anxiety in EPM and memory disturbances in Morris water maze test) in the two cases: CMS and combined CMS+CFA to determine the possibility of developing depressive-like symptoms by mice. Based on bibliographic data and previous studies in this area of research, we tried to explain the mechanisms involved in each situation.

\section{Materials and Methods}

\section{Animals}

The experiments were performed using adult female mice Mus musculus (purchased from Pasteur Institute, Algiers) weighing 29 to

*Corresponding author: Hacene FRIH, faculté des Sciences, Département de Biologie, Laboratory of Applied Neuro-Endocrinology, Université Badji Mokhtar Annaba, Algeria, E-mail: frihhacene@yahoo.fr

Received December 12, 2012; Accepted January 16, 2013; Published January 20, 2013

Citation: Frih H, Bensaci L, Djenidi R, Rachedi BA, Tahraoui A, et al. (2013) Freund's Complete Adjuvant (FCA) Could Reverse the Depressive-Like Symptoms Induced by Chronic Mild Stress (CMS) in Mice. J Neurol Neurophysiol 4: 143. doi:10.4172/2155-9562.1000143

Copyright: @ 2013 Frih H, et al. This is an open-access article distributed unde the terms of the Creative Commons Attribution License, which permits unrestricted use, distribution, and reproduction in any medium, provided the original author and source are credited. 
$32 \mathrm{~g}$ at the beginning of the experiment. The animals were housed with food and water freely available and maintained under a standard $12 / 12$ hour light/dark cycle (lights on at 0700), with ambient temperature set at $25 \pm 2{ }^{\circ} \mathrm{C}$ and relative humidity $(50 \%)$. Animals were softly handled 3 to 5 minutes per day by the experimenter before the onset of the experiment. The experimental protocol was approved by the Scientific Committee of our faculty which is consistent with the principles of Animal Health (NIH Publication No. 85-23, revised 1985).

After an acclimatization period of 15 days, 24 female mice were divided into 4 groups: a control group of 7 untreated animals, a group of 9 mice submitted to chronic mild stress (CMS) for 6 weeks and a group of 8 mice chronically stressed and treated with complete Freund's adjuvant (CMS+CFA). Body weights were measured weekly during the CMS procedure. The experimental protocol was shown in (Table 1).

The depression-related behaviors were assessed before (baseline) and after the CMS procedure by the open-field, the elevated plus-maze (EPM) and the water maze tests.

\section{Chronic mild stress (CMS)}

Chronic mild stress (CMS) was used according to the literature [18]. The 2 groups CMS and CMS+CFA were submitted to 40 days of chronic mild stress. Several stressors have been used: food deprivation, water deprivation, forced swimming, flashing light, isolation, wet litter and wet litter at $4^{\circ} \mathrm{C}$. The stress was applied at times that change every day, in order to minimize its predictability. Control mice were kept intact in their cages for 40 days, receiving only usual care, food and water. The program stressors and daily duration are listed in Table 1.

\section{Chronic inflammation by complete Freund's adjuvant}

Freund's adjuvant is an emulsion of water and oil. When mixed with inactivated and dried Mycobacterium tuberculosis we obtain the complete Freund's adjuvant. From a stock solution of $25 \%$ ABS, we prepared a $1 \%$ solution in sterile distilled water and we mixed it with the same volume of Freund's complete adjuvant. Each mouse received a $100 \mu \mathrm{l}$ subcutaneous injection of this mixture, with a dose of $0.03 \mathrm{mg} /$ $\mathrm{ml}$ of CFA. Mice received 21 days later a $2^{\text {nd }}$ intradermal injection of 30 $\mu \mathrm{g}$ of $\mathrm{ABS}$ in a volume of $0.05 \mathrm{ml}$ of sterile water into the right posterior footpad.

\section{Behavioral study}

Open field test: The open field [19] apparatus measured $70 \times 70 \mathrm{~cm}$ with $40 \mathrm{~cm}$ walls of Plexiglas. Squares of $10 \times 10 \mathrm{~cm}$ were drawn on the floor and divided it into a central zone and a peripheral zone of 35 $\mathrm{cm}$ each. The test was performed for $5 \mathrm{~min}$ by placing the animal in the center of the field, and measuring the number of squares crossed and the time spent in each zone. Test sequences were recorded and the videos were used to calculate different parameters. After each mouse, the open field was cleaned with $70 \%$ alcohol. Ten variables were measured: Center square, periphery and border duration, Center square, periphery and border entries, Rearing frequency, Traveled distance, Freezing duration and Locomotion index.

Elevated plus maze test: The elevated plus maze test [20] is used to measure the degree of anxiety in rodents. It is composed of four arms $(50 \times 10 \mathrm{~cm})$, two open arms perpendicular to two closed arms with $40 \mathrm{~cm}$ high walls of Plexiglas. The intersection of the four arms (central area) is a square of $10 \times 10 \mathrm{~cm}[20,21]$. The apparatus was elevated of $50 \mathrm{~cm}$ from the ground. The test was performed for $5 \mathrm{~min}$ by placing the animal in the central area facing an open arm. Since the mouse fears the empty and high spaces, his exploration of open arms shows a less anxious behavior. On the contrary, the more the animal remains in the closed arms, his behavior are known to be anxious [22]. The $5 \mathrm{~min}$ sequences were recorded by a video camera to measure the following parameters: Open arms duration, Closed arms duration, Open arms entries, Closed arms entries, Head dipping frequency, Rearing frequency and Freezing duration $[23,24]$.

The Morris water maze: Morris water maze is used to identify and measure spatial learning and memory in rodents [25]. The apparatus is a circular pool of $120 \mathrm{~cm}$ diameter and $60 \mathrm{~cm}$ deep, mounted on a stand and divided into 4 quadrants. One of them has a platform slightly submerged at $1 \mathrm{~cm}$ below the water surface, the target quadrant. The MWM is filled with water up to $30 \mathrm{~cm}$. The water temperature is 22 to $32^{\circ} \mathrm{C}$. The test consists of 4 days with 5 runs per day during the first 3 days. The fourth day, the mice have two passages with platform without platform and 3 passages. During each test, the animal is placed in the water at the periphery in different places, and swim to find the platform, then it is removed from the water. Video recordings have been performed for 60 seconds. Five parameters were recorded: Time

\begin{tabular}{|c|c|c|}
\hline Day & Stressing factor & Duration \\
\hline 1 & Water deprivation & $24 \mathrm{~h}$ \\
\hline 2 & Food deprivation & $24 \mathrm{~h}$ \\
\hline 3 & Isolation & $24 \mathrm{~h}$ \\
\hline 4 & Isolation & $24 \mathrm{~h}$ \\
\hline 5 & Isolation & $24 \mathrm{~h}$ \\
\hline 6 & Flashing light & $3 \mathrm{~h}$ \\
\hline 7 & Food deprivation & $24 \mathrm{~h}$ \\
\hline 8 & Forced swimming & $10 \min$ \\
\hline 9 & Wet litter & $1 \mathrm{~h}$ \\
\hline 10 & Water deprivation & $24 \mathrm{~h}$ \\
\hline 11 & No stress & - \\
\hline 12 & No stress & - \\
\hline 13 & Wet litter $4^{\circ} \mathrm{C}$ & $2 \mathrm{~h}$ \\
\hline 14 & Flashing light & $2 \mathrm{~h} 1 / 2$ \\
\hline 15 & Food deprivation & $24 \mathrm{~h}$ \\
\hline 16 & Forced swimming & $15 \min$ \\
\hline 17 & Isolation & $24 \mathrm{~h}$ \\
\hline 18 & Isolation & $24 \mathrm{~h}$ \\
\hline 19 & Isolation & $24 \mathrm{~h}$ \\
\hline 20 & Water deprivation & $24 \mathrm{~h}$ \\
\hline 21 & Food deprivation & $24 \mathrm{~h}$ \\
\hline 22 & Flashing light & $3 \mathrm{~h}$ \\
\hline 23 & Wet litter & $1 \mathrm{~h}$ \\
\hline 24 & Isolation & $24 \mathrm{~h}$ \\
\hline 25 & Isolation & $24 \mathrm{~h}$ \\
\hline 26 & Wet litter $4^{\circ} \mathrm{C}$ & $1 \mathrm{~h} 1 / 2$ \\
\hline 27 & Forced swimming & $10 \min$ \\
\hline 28 & Flashing light & 3 h $1 / 2$ \\
\hline 29 & No stress & - \\
\hline 30 & Food deprivation & $24 \mathrm{~h}$ \\
\hline 31 & Wet litter & $1 \mathrm{~h}$ \\
\hline 32 & Flashing light & $2 \mathrm{~h}$ \\
\hline 33 & Water deprivation & $24 \mathrm{~h}$ \\
\hline 34 & Wet litter $4^{\circ} \mathrm{C}$ & $2 \mathrm{~h}$ \\
\hline 35 & Forced swimming & $10 \min$ \\
\hline 36 & Isolation & $24 \mathrm{~h}$ \\
\hline 37 & Isolation & $24 \mathrm{~h}$ \\
\hline 38 & No stress & - \\
\hline 39 & Flashing light & $3 \mathrm{~h}$ \\
\hline 40 & Forced swimming & $10 \min$ \\
\hline
\end{tabular}

Table 1: Program of stressors and duration applied every day. 
Citation: Frih H, Bensaci L, Djenidi R, Rachedi BA, Tahraoui A, et al. (2013) Freund's Complete Adjuvant (FCA) Could Reverse the Depressive-Like Symptoms Induced by Chronic Mild Stress (CMS) in Mice. J Neurol Neurophysiol 4: 143. doi:10.4172/2155-9562.1000143

in the target quadrant, Latency duration, Entries in the target quadrant, Retention index and Traveled distance.

Statistical analysis of results: Data are presented as mean \pm SEM. Data were analyzed by one-way ANOVA and Newman and Keuls as the post hoc test, while the results from binding assays were analyzed by the Student's $t$ test. Results were considered significant at $\mathrm{p}<0.05$.

\section{Results}

\section{Body weight}

Animal's body weight was measured every 7 days of the chronic mild stress (Table 2). Mice of all groups (CMS and CFA+CMS) had a significant decrease in the relative weight between the first measurement the first day (D1) of CMS and the end (D41) of CMS $(\mathrm{P}<0.05)$. We also noted that the relative weight of CMS and CFA groups showed significant differences compared to control $(\mathrm{P}<0.05)$, while the group CMS+CFA showed highly significant differences compared to control $(\mathrm{P}<0.01)$.

\section{Variation in organs weight}

After mice sacrifice of all groups organs were removed and weighed. Their relative weights $(\mathrm{g} / 100 \mathrm{~g} \mathrm{LW})$ are given in Table 2. The CMS showed a very highly significant decrease in the relative adrenal weight (control: $0.0004 \pm 0.00004$ vs. CMS: $0.0001 \pm 0.00005(\mathrm{P}<0.001)$ ), a very highly significant increase of liver (control: $0.015 \pm 0.0025$ vs. CMS: $0.18 \pm 0.003(\mathrm{P}<0.001))$, the relative weight of the spleen, thymus and kidney increased significantly [spleen: control: 0,0015 $\pm 0,0003$ vs. CMS: $0,0023 \pm 0,0005(\mathrm{P}<0.05)$; thymus: control: 0,0011 $\pm 0,0007$ vs. CMS: $0,0026 \pm 0,00035(\mathrm{P}<0.01)$; kidney: control: $0,0039 \pm 0,00015$ vs. CMS: $0,0045 \pm 0,0006(\mathrm{P}<0.05)]$.

The injection of CFA in CMS group caused a significant reverse in liver relative weight $(0,016 \pm 0,0008$ (ns), thymus $(0,0009 \pm 0,0003$ $(\mathrm{P}<0.05))$ and adrenals $(0,0003 \pm 0,0001(\mathrm{~ns}))$ (Table 2).

\section{Parameters variations in elevated plus maze test (EPM) and open field test}

Anxiety behaviors of mouse were measured by the time spent in the open arms and open arms entries in EPM. As presented in Table 3 , the CMS showed a significant decrease of these two parameters (Open arms duration (sec): control: $115,18 \pm 22,669$ vs. CMS: 70,37 $\pm 12,93(\mathrm{P}<0.01)$; Open arms entries: control: $37,37 \pm 7,686$ vs. CMS: $17,87 \pm 2,68(\mathrm{P}<0.001))$. The decrease in these two parameters indicates that the chronic mild stress has an anxiogenic effect. These effects are reversed by CFA (Open arms duration (sec): 110,00 $\pm 11,33$ (ns); Open arms entries: control: $28,68 \pm 3,84(\mathrm{P}<0.05))$. The loccomotor activity estimated by freezing duration $(\mathrm{sec})$ indicates that mice CMS are less active than CMS+CFA (Table 3).

These results were confirmed in the Open field test (Table 4) when it showed that the CMS induced the behavioral changes cited above. In the Open field test, the traveled distance had been significantly reduced and associated with a decrease of the entries on the center and a shorter time spent in this anxiolytic compartment of the device.

\section{Parameters variations in Morris water maze}

Latency of access to the platform: Before CMS mice had a much reduced latency time access to the platform compared with mice after CMS, and this time decreased gradually during the 3 days of testing before the CMS (Figure 2). This latency time was very highly significant $(\mathrm{P}<0.001)$. When the platform was absent (the last 3 passages of the fourth day), stressed mice (after CMS) showed a significant increase $(\mathrm{P}<0.05)$ of latency time compared to mice before CMS. By cons, CFA+CMS mice have a very highly significant increase $(\mathrm{P}<0.001)$ in latency after CMS compared to control (Figure 2). These results indicate a state of degradation of the memory of animals in CMS group with partial restoration in CMS+CFA group.

\begin{tabular}{|l|l|l|l|}
\hline & Control & CMS & CMS+CFA \\
\hline Liver & $0,015 \pm 0,0025$ & $0,18 \pm 0,003^{* *}$ & $0,016 \pm 0,0008 \mathrm{NS}$ \\
\hline Spleen & $0,0015 \pm 0,0003$ & $0,0023 \pm 0,0005^{*}$ & $0,0027 \pm 0,0011^{\star}$ \\
\hline Thymus & $0,0011 \pm 0,0007$ & $0,0026 \pm 0,00035^{* *}$ & $0,0009 \pm 0,0003^{*}$ \\
\hline Ovaries & $0,0005 \pm 0,0007$ & $0,0004 \pm 0,00014 \mathrm{NS}$ & $0,0005 \pm 0,0007 \mathrm{NS}$ \\
\hline Brain & $0,003 \pm 0,0007$ & $0,0035 \pm 0,0002^{*}$ & $0,0034 \pm 0,0002^{*}$ \\
\hline Kidney & $0,0039 \pm 0,00015$ & $0,0045 \pm 0,0006^{*}$ & $0,0043 \pm 0,0003^{*}$ \\
\hline Adrenals & $0,0004 \pm 0,000045$ & $0,0001 \pm 0,00005^{* * *}$ & $0,0003 \pm 0,0009 \mathrm{NS}$ \\
\hline Body weight & $0,34 \pm 0,00299$ & $0,29 \pm 0,0027$ & $0,32 \pm 0,00341$ \\
\hline
\end{tabular}

NS: Not significant, "Significant $(P<0.05),{ }^{* *}$ Highly significant $(P<0.01),{ }^{* * *}$ Very highly significant $(P<0.001)$

Table 2: Average relative weight of organs $(g / 100 \mathrm{~g} L W)$ in stressed mice (CMS), treated with CFA and Control.

\begin{tabular}{|l|l|l|l|}
\hline \multicolumn{1}{|c|}{ Groups } & $\begin{array}{l}\text { CONTROL } \\
13 \text { days before } \\
\text { CMS }\end{array}$ & $\begin{array}{l}\text { CMS+CFA } \\
\text { D39 of CMS }\end{array}$ & $\begin{array}{l}\text { CMS } \\
\text { D39 of CMS }\end{array}$ \\
\hline Parameters & $37,37 \pm 7,686$ & $28,68 \pm 3,84^{*}$ & $17,87 \pm 2,68^{* * *}$ \\
\hline $\begin{array}{l}\text { Open arms entries } \\
\text { Open arms duration }\end{array}$ & $115,18 \pm 22,669$ & $110,00 \pm 11,33$ & $70,37 \pm 12,93^{* *}$ \\
\hline Open arms returns & $0,31 \pm 0,602$ & $0 \mathrm{NS}$ & $0 \mathrm{NS}$ \\
\hline Closed arms entries & $47,24 \pm 3,80$ & $31,57 \pm 1,605^{* *}$ & $23,62 \pm 2,438^{* * *}$ \\
\hline $\begin{array}{l}\text { Closed arms duration } \\
\text { (sec) }\end{array}$ & $147,31 \pm 23,2$ & $142,43 \pm 54,058^{*}$ & $155,62 \pm 47,074^{* * *}$ \\
\hline Closed arms returns & $1,685 \pm 0,623$ & $0^{*}$ & $0^{*}$ \\
\hline Center entries & $17,50 \pm 5,428$ & $15,00 \pm 3,265 \mathrm{NS}$ & $13,87 \pm 3,907^{*}$ \\
\hline Center duration (sec) & $25,12 \pm 7,246$ & $36,43 \pm 15,988^{* *}$ & $40,12 \pm 18,473^{* *}$ \\
\hline Head dipping frequency & $16,81 \pm 7,909$ & $12,00 \pm 6,244^{*}$ & $14,00 \pm 4,407^{*}$ \\
\hline Rearing frequency & $17,44 \pm 6,5$ & $14,55 \pm 5,68 \mathrm{NS}$ & $15,62 \pm 7,501 \mathrm{NS}$ \\
\hline Freezing duration (sec) & 0 & $12,57 \pm 9,72^{* * *}$ & $28,37 \pm 7,82^{* * *}$ \\
\hline
\end{tabular}

NS: Not significant, "'Significant $(P<0.05)$, "'Highly significant $(P<0.01)$, " Very highly significant $(\mathrm{P}<0.001)$

Table 3: Parameters variation in Elevated plus maze test (EPM) in Control, CMS and CMS+CFA groups, 13 days before CMS and in D39 of the CMS.

\begin{tabular}{|l|l|l|l|}
\hline \multicolumn{1}{|c|}{ Groups } & $\begin{array}{l}\text { Control } \\
13 \text { days before CMS }\end{array}$ & $\begin{array}{l}\text { CMS+CFA } \\
\text { D39 of CMS }\end{array}$ & $\begin{array}{l}\text { CMS } \\
\text { D39 of CMS }\end{array}$ \\
\hline $\begin{array}{l}\text { Parameters } \\
\text { Total distance (cm) }\end{array}$ & $2681,11 \pm 1362,217$ & $240,50 \pm 58,356^{* * *}$ & $227,11 \pm 86,128^{* * *}$ \\
\hline $\begin{array}{l}\text { Center square } \\
\text { entries }\end{array}$ & $10,12 \pm 3,854$ & $6,87 \pm 3,796^{*}$ & $6,33 \pm 3,774^{*}$ \\
\hline Periphery entries & $22,65 \pm 10,289$ & $14,00 \pm 6,568^{* *}$ & $12,43 \pm 6,399^{* *}$ \\
\hline Border entries & $22,65 \pm 10,289$ & $9,62 \pm 4,438^{* * *}$ & $12,33 \pm 7,745^{* *}$ \\
\hline $\begin{array}{l}\text { Rearing frequency } \\
\text { Center square } \\
\text { duration (sec) }\end{array}$ & $27,23 \pm 6,887$ & $22,75 \pm 10,579^{*}$ & $21,22 \pm 7,102^{*}$ \\
\hline $\begin{array}{l}\text { Periphery duration } \\
\text { (sec) }\end{array}$ & $15,59 \pm 4,651$ & $12,75 \pm 6,713^{*}$ & $12,55 \pm 9,862^{*}$ \\
\hline $\begin{array}{l}\text { Border duration } \\
\text { (sec) }\end{array}$ & $239,89 \pm 25,585$ & $12,00 \pm 6,676^{* * *}$ & $25,87 \pm 21,383^{* * *}$ \\
\hline $\begin{array}{l}\text { Locomotion index } \\
\text { Freezing duration } \\
\text { (sec) }\end{array}$ & $102,75 \pm 4,856$ & $81,95 \pm 32,502^{* *}$ & $71,10 \pm 31,372^{* *}$ \\
\hline
\end{tabular}

NS: Not significant, "Significant $(P<0.05),{ }^{* *}$ Highly significant $(P<0.01),{ }^{* *}$ Very highly significant $(P<0.001)$.

Table 4: Variations in the parameters of Open field test in Control, CFA+CMS, and CMS mice 13 days before CMS and in D39 of CMS. 
Retention index: During the last 3 trials of the fourth day, the platform was removed from the pool. Travel mice were followed for 60 seconds, in order to assess their research strategy of the platform, and their ability to recall its location. The retention index in the CMS and CFA+CMS group showed a significant decrease $(\mathrm{P}<0.05)$ (Figure 2) compared to Control. This decrease indicated a deterioration of spatial memory.

Retention index $=($ Latency $) /($ Average time in the 3 other quadrants $)$

Distance: The mean traveled distances between the release point and the platform are presented in Figure 2. During the first 3 days of testing with the platform, there was a highly significant increase in the distances traveled by the animals after CMS (CMS and CMS+CFA) $(\mathrm{P}<0.01)$ compared to Control. The fourth day, when the platform was removed, all mice after CMS (CMS and CMS+CFA) covered a greater distance than Control, showing a decrease of their memory. However, the performance of the two groups CMS and CMS+CFA, after the chronic mild stress did not show any improvement over time despite daily workouts. The number of entries and the time spent in the target quadrant during the first 3 days of the test, showed no significant variation in all groups (Control, CFA+CMS, CMS). But during the fourth day, the mice after CMS (CMS and CMS+CFA) showed a significant reduction $(\mathrm{P}<0.05)$ of the number of entries in the target quadrant, i.e. locomotor activity.

\section{Discussion}

Numerous studies have been conducted to understand the role of the different factors contributing to the development of depression and anxiety [26], an experimental model most commonly used to assess the effects of depression in rodents is the CMS (Chronic mild stress) originally developed by Willner $[27,28]$. Mice exposed to CMS for 40 days showed a depression characterized by behavioral changes symptomatic of depression in humans, such as a significant reduction in locomotion [27]. Anhedonia, a major symptom of depression, cooccurs to alterations in locomotor activity and body weight loss [29]. Exposure to chronic stress can produce severe psychological disorders such as anxiety or significant disruption of learning and memory, associated with depression [30].

Our results showed that the CMS induced behavioral changes cited above. In the Open field test (Table 4), the traveled distance has been significantly reduced and associated with a decrease of the entries on the center and a shorter time spent in this anxiolytic compartment of the device. The Open field test is a device intended to evaluate both locomotor activity and anxiety levels in mice [31]. This test evaluates the reaction of an animal towards a new and spacious environment. It creates a conflict between the tendency of rodents to find a place to hide, and their aversion to open spaces. Therefore anxious animals tend to spend more time in the corners and the periphery of the device rather than in the center [32]. Other results corroborating the previous observation are those obtained in the Elevated plus maze test (Table 3). Mice are afraid of heights and naturally take refuge in the closed arms of the device that provide greater security. The less anxious animals flow more freely into the open arms of the device [32]. The EPM test showed an increase of anxiety levels in stressed mice (CMS) expressed by a decrease in the number of entries and the time spent into the open arms. The increased immobility time of stressed mice indicate a decrease in locomotor activity. Regarding the evolution of body weight (Figure 1), we found that CMS mice show a loss of weight after only 7 days of CMS and the curve of the weight remains below that Control throughout the experiment. This indicates that the depression animal model has been successfully established.

CMS not only induces depressive-like behaviors but also neurocognitive deficits. Therefore, it is important to examine the associations between reduced neurogenesis and neurocognitive functioning following CMS. Thus, CMS increases IL- $1 \beta$, TNF- $\alpha$ and IL- 6 and provokes neurocognitive defects, as estimated by the water maze task, the object recognition and object location test [33]. In another study, CMS significantly reduced the surviving of new brain cells in the hippocampus and the subventricular zone and impairment in hippocampus-dependent learning, while hippocampus-independent learning was not affected [34]. While CMS impaired hippocampusdependent learning and reduced neurogenesis no direct causative relationships could be established between the behaviors and reduced neurogenesis [34].

In Morris water maze, we found that the CMS can also induce impaired learning and spatial memory through the measurement of various parameters, i.e. the number of entries in the target quadrant, the time spent in the target quadrant, the latency, the distance traveled and the retention time (Figure 2). When testing the 4 th day without platform, where the movements of mice were monitored for 60 seconds in order to evaluate their platform search strategy and their ability to recall its location, we recorded in the CMS group a reduced locomotor activity (number of entries and time spent in the target quadrant), which explains the state of deficit of neuronal processes in sensory integration which reflects a dysfunction in spatial memory [30]. The retention index was significantly decreased. On the contrary, the traveled distance increased.

From our results and previous studies on the CMS, we can confirm that the CMS causes a depression characterized by an increased anxiety associated with a decreased locomotion [35] and a degradation of memory [30]. Among the hypotheses proposed to explain the degradation inherent to the CMS, there is the neurotoxicity of some products of stress, as the production of neurotoxins of mediators of inflammation, pro inflammatory cytokines, free radicals by monocytes and astrocytes, the activation of glutamatergic neuronal receptors NMDA, neuronal apoptosis, alteration of the blood-brain barrier (BBB) by circulating cytokines and oxidative shock responsible for neuronal dysfunction suggested as a possible convergence of these factors to a common path [36-39].

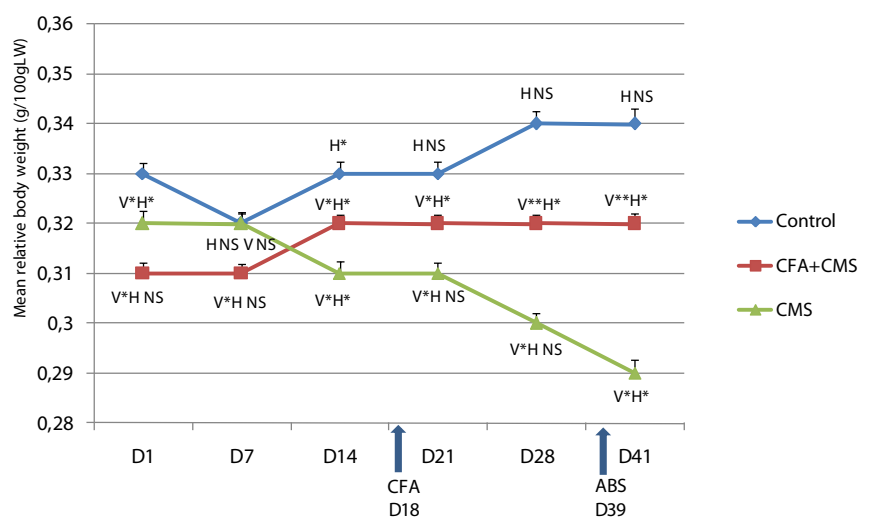

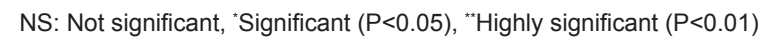
$\mathrm{H}$ : horizontal comparison; V: vertical comparison

Figure 1: Evolution of mean body weight gain ( $\mathrm{g} / 100 \mathrm{~g} \mathrm{LW})$ in Control mice, treated with CFA and stressed (CMS). 

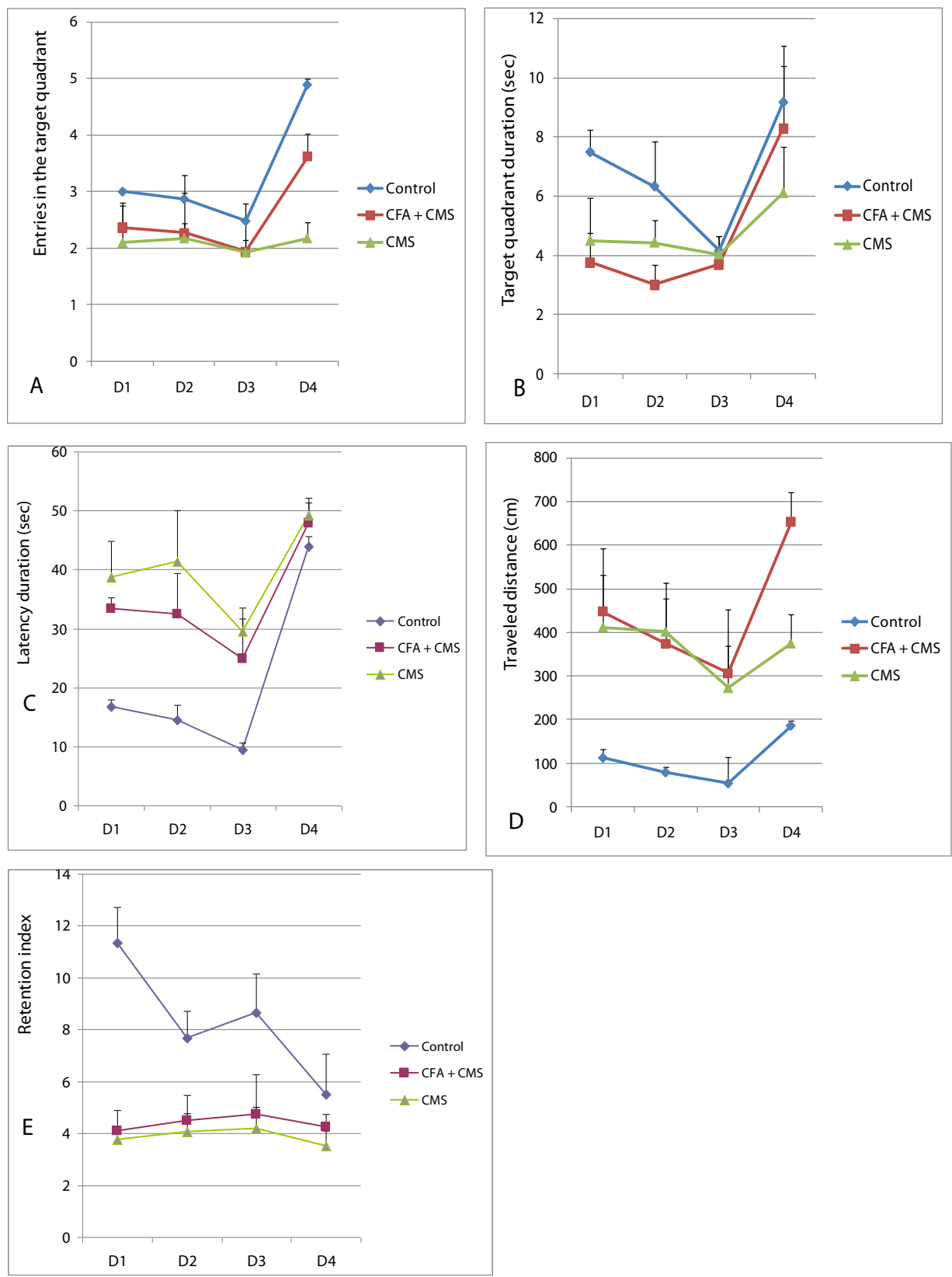

Figure 2: Number of entries in the target quadrant (A), Target quadrant duration (sec) (B), Latency duration (sec) (C), Travelled distance (cm) (D) and Retention index $(E)$ in the Morris water maze test in Control mice, treated with CFA, and stressed with the CMS.

The inflammatory process may contribute to the damage of the BBB. Indeed, the activation of microglia can release several toxic substances including RNOS, cytokines and glutamate, contributing to endothelial damage. In addition, cytokines such as IL- $1 \beta$ and TNF- $\alpha$ stimulate the expression of cell adhesion molecules such as ICAM-1, leading to extravasations of leukocytes in the brain, also generating toxic substances similar to those of activated microglia.

The state of inflammation associated with depression is not limited to alterations of the $\mathrm{BBB}$, it is also found in the brain where the expression of cytokines is different compared to peripheral tissues [29]. Stress induces inflammatory responses in various brain regions producing pro-inflammatory cytokines such as TNF- $\alpha$, IL- 6 and IL-1 $[27,40]$. This production is associated with a decrease in BDNF (brain- derived neurotrophic factor) and neurogenesis [41]. Cytokines are constitutively expressed in the central nervous system (CNS), acting as modulators of neuronal functions and neuronal survival, and in the case of chronic stress, they become harmful [29]. Many studies showed that stress accelerates apoptosis of neurons and causes changes in the structure and function of the hippocampus in rodents. The hippocampus is the common target of many antidepressants [27]. CMS reduces adult hippocampal neurogenesis [28] and oxidative stress in vivo causes a deterioration of the hippocampus, inducing anxiety behavior and a decrease in locomotor activity in mice [42].

In general, the CMS can produce severe psychological disorders (anxiety, depression, etc.) and major disorders of learning and memory that have been allocated to various neurobiological factors [30]. For 
some authors, chronic stress leads particularly to a dysfunction of the prefrontal cortex. Other authors mentioned especially the importance of functional impairment of the hippocampus to explain memory problems resulting from stress [30]. In addition, inflammation may stimulate the activity of the hypothalamo pituitary axis (HPA) via both the direct action of cytokines on the brain and induction of resistance to glucocorticoids [27]. HPA hyperactivation associated with impaired feedback inhibition is the most widely observed in depressed patients. Glucocorticoids such as cortisol are vital hormones released in response to stress and regulate metabolism and immunity but also neuronal survival and neurogenesis.

The experimental and clinical studies have shown that proinflammatory cytokines cause HPA hyperactivation, interruption of sleeping and appetite, weakened sexual activity, impair memory and disrupt neurotransmission, inducing anxiety and behavior depression [43]. Anorexia is also observed after injection of CRF in the para ventricular nucleus (PVN) and the pre-treatment of animals with CRF antagonists ( $\alpha$-helical CRF) or anti-CRF, blocks the effects of stress and anorexia induced by serotonin (5-HT), suggesting that activation of 5-HT leads to the secretion of CRF, which in turn inhibits food intake [44].

Studies in depressed patients showed impairment of acquired immune responses, especially $\mathrm{T}$ cell responses. Some data suggest that activated $\mathrm{T}$ cells may have an important neuroprotective role in the context of stress and inflammation [41]. These data clearly justify our approach in which we have chosen an antigenic stimulation associated with CMS. It is well known that the subcutaneous inoculation of complete Freund's adjuvant (CFA) containing antigen of Mycobacterium induced inflammation in rodents. This inflammation causes peripheral and central sensitization [45]. The adjuvant induced inflammation is considered as a model for T-cell dependent, autoimmune diseases [17] and the core symptoms constitute the sickness behavior, or behavioral changes that accompany immune response [17]. Very recently, Parent et al. [45] used CFA to cause chronic inflammatory pain in rats and confirmed that this model is very similar to CMS regarding the induction of symptoms of depression and anxiety.

In this study, the injection of CFA in mice submitted to a CMS has provided a partial repair of the memory in the Morris water maze expressed by a number of entries in the target quadrant more significant compared to the CMS group (Figure 2). The time in the target quadrant is also superior. The latency time and the traveled distance are less important. The results of other behavioral tests (Open field and Elevated plus maze) are comparable and also showed partial repair in CMS+CFA group. Regarding the evolution of the body weight (Figure 1) CFA+CMS mice show a very significant weight restoration. This variation in body weight is associated with a remarkable collapse of thymus relative weight and restored adrenal weight (Table 2).

Studies indicate that the administration of glucocorticoids in vivo results in a pronounced thymic involution in mice, whereas adrenalectomy leads to a significant weight gain of the thymus and spleen and an increase in the number of splenic T cells [46]. In return, the thymus may also affect adrenal function and Hirokawa et al. found that the implementation of newborn thymus increased adrenal weight in nude mice [47]. According to Arzt et al. [48] and Karanth et al. [49], cytokines may have an indirect effect by inducing the secretion of hypothalamic corticotropin releasing hormone (CRH), which plays an important trophic role in the adrenal activity. They showed that the interleukins IL-2 and IL-6 induce in vitro proliferation of anterior pituitary cells, as well as the secretion of growth hormone
$(\mathrm{GH})$, prolactin (PRL) and adrenocorticotropic hormone (ACTH). Reduction of thymic function may increase the synthesis of IL-1 [43]. In addition, IL- 1 induced changes in certain neurotransmitter systems similar to those observed in thymectomized rats [43].

Several hypothesis can be advanced to explain the healing effect of Freund's complete adjuvant obtained in our study. It has been suggested that an imbalance between the pro-inflammatory and antiinflammatory cytokines caused by CMS can lead to lasting changes in the anatomy and function of the brain, and thus long-term impairment of mood, cognition and behavior [29]. And it is possible that the CFA administered to CMS mice would reverse the imbalance between pro-inflammatory and anti-inflammatory cytokines and this effect affect neuronal regeneration. It was also shown that the activation of microglia is an early phenomenon, preceding the BBB disruption [50]. However, the activation of microglia by CFA, although often associated with cytotoxicity could possibly protect the BBB against stress.

Moreover TNF- $\alpha$ may via TNF-receptor 1 (TNF-R1) activate MAPK (mitogen activated protein kinases) and increase NFKB (nuclear factor $\kappa B)$ causing neuronal apoptosis [51], whereas activation of the TNF-R2 probably results in neuroprotective effects [52]. Thus, the two TNF receptors may exhibit antagonistic functions on neurodegenerative processes whereby TNF-R1 aggravates and TNF-R2 reduces neuronal cell loss, respectively $[51,52]$. Both TNF-R1 and TNF-R2 may induce the NFkB pathway, be it with distinguishable kinetics and upstream activating components. For example, TNF-R1 induces a transient NFאB activation, whereas TNFR2 facilitates long-term phosphatidylinositol 3-kinase-dependent NFkB activation [53]. Munhoz et al. [54] reported that TNF $\alpha$ plays a key role on the persistence of brain cellular damage two weeks after repeated stress. The role of IL- 6 in response to external stressors is very complex. IL-6 may protect neurons but in other conditions may have detrimental effects. For example, intracerebral administration of IL-6 before exposition of rodents to ischemic or excitotoxic insults inhibits neuron death [55]. Mice with chronic IL-6 overexpression, show marked neurodegeneration and psychological distress that are related to increased IL-6 plasma and/or brain concentrations [56].

\section{References}

1. Kubera M, Obuchowicz E, Goehler L, Brzeszcz J, Maes M (2011) In animal models, psychosocial stress-induced (neuro)inflammation, apoptosis and reduced neurogenesis are associated to the onset of depression Prog NeuroPsychopharmacol Biol Psychiatry 35: 744-759.

2. Maes M (1995) Evidence for an immune response in major depression: a review and hypothesis. Prog Neuropsychopharmacol Biol Psychiatry 19: 11-38.

3. Maes M (2008) The cytokine hypothesis of depression: inflammation, oxidative \& nitrosative stress (IO\&NS) and leaky gut as new targets for adjunctive treatments in depression. Neuro Endocrinol Lett 29: 287-291.

4. Maes M, Smith R, Scharpe S (1995) The monocyte-T-lymphocyte hypothesis of major depression. Psychoneuroendocrinology 20: 111-116.

5. Maes M, Yirmyia R, Noraberg J, Brene S, Hibbeln J, et al. (2009) The inflammatory \& neurodegenerative (I\&ND) hypothesis of depression: leads for future research and new drug developments in depression. Metab Brain Dis 24: 27-53.

6. Anisman H (2009) Cascading effects of stressors and inflammatory immune system activation: implications for major depressive disorder. J Psychiatry Neurosci 34: 4-20.

7. Miller AH, Maletic V, Raison CL (2009) Inflammation and its discontents: the role of cytokines in the pathophysiology of major depression. Biol Psychiatry 65: 732-741.

8. Willner P, Towell A, Sampson D, Sophokleous S, Muscat R (1987) Reduction of sucrose preference by chronic unpredictable mild stress, and its restoration by a tricyclic antidepressant. Psychopharmacology (Berl) 93: 358-364. 
Citation: Frih H, Bensaci L, Djenidi R, Rachedi BA, Tahraoui A, et al. (2013) Freund's Complete Adjuvant (FCA) Could Reverse the Depressive-Like Symptoms Induced by Chronic Mild Stress (CMS) in Mice. J Neurol Neurophysiol 4: 143. doi:10.4172/2155-9562.1000143

9. Willner P (1997) Validity, reliability and utility of the chronic mild stress mode of depression: a 10-year review and evaluation. Psychopharmacology (Berl) 134: 319-329.

10. Holmes JE, Miller NE (1963) Effects Of Bacterial Endotoxin On Water Intake, Food Intake, And Body Temperature In The Albino Rat. J Exp Med 118: 649658.

11. Hart BL (1988) Biological basis of the behavior of sick animals. Neurosci Biobehav Rev 12: 123-137.

12. Maier SF, Wiertelak EP, Martin D, Watkins LR (1993) Interleukin-1 mediates the behavioral hyperalgesia produced by lithium chloride and endotoxin. Brain Res 623: 321-324.

13. Kelley KW, Bluthé RM, Dantzer R, Zhou JH, Shen WH, et al. (2003) Cytokineinduced sickness behavior. Brain Behav Immun 17 Suppl 1: S112-118.

14. Yirmiya R (1996) Endotoxin produces a depressive-like episode in rats. Brain Res 711: 163-174.

15. Exton MS (1997) Infection-induced anorexia: active host defence strategy. Appetite 29: 369-383.

16. Qin L, Wu X, Block ML, Liu Y, Breese GR, et al. (2007) Systemic LPS causes chronic neuroinflammation and progressive neurodegeneration. Glia 55: 453462

17. Garcia-Bonacho M, Esquifino Al, Castrillon PO, Toso CR, Cardinali DP (2000) Age-dependent effect of Freund's adjuvant on 24-hour rhythms in plasma prolactin, growth hormone, thyrotropin, insulin, follicle-stimulating hormone, luteinizing hormone and testosterone in rats. Life Sciences 66: 1969-1977.

18. Gamaro GD, Manoli LP, Torres IL, Silveira R, Dalmaz C (2003) Effects of chronic variate stress on feeding behavior and on monoamine levels in different rat brain structures. Neurochem Int 42: 107-114.

19. Hall CS (1934) Emotional behavior in the rat. Defecation and urination as measures of individual difference in emotionality. J Comp Physical 18 : 385403.

20. MONTGOMERY KC (1955) The relation between fear induced by novel stimulation and exploratory behavior. J Comp Physiol Psychol 48: 254-260.

21. Roy V (2002) Contribution to the study of emotional conduits in the rat: use of the handling postnatal and the approach etho- expérimental of the behavior. Thesis of doctorate. University of Rouen.

22. Pellow S, Chopin P, File SE, Briley M (1985) Validation of open:closed arm entries in an elevated plus-maze as a measure of anxiety in the rat. J Neurosci Methods 14: 149-167.

23. Dawson IA, Roth S, Artavanis-Tsakonas S (1995) The Drosophila cell cycle gene fizzy is required for normal degradation of cyclins $A$ and $B$ during mitosis and has homology to the CDC20 gene of Saccharomyces cerevisiae. J Cell Biol 129: 725-737.

24. Weiss A, Herzig A, Jacobs H, Lehner CF (1998) Continuous Cyclin E expression inhibits progression through endoreduplication cycles in Drosophila. Curr Biol 8: 239-242.

25. Morris RGM (1981) Spatial Localization Does Not Require the Presence of Local Cues. Learning and Motivation 12: 239-260.

26. McEwen BS (2005) Glucocorticoids, depression, and mood disorders: structural remodeling in the brain. Metabolism 54: 20-23.

27. Zunszain PA, Anacker C, Cattaneo A, Carvalho LA, Pariante CM (2011) Glucocorticoids, cytokines and brain abnormalities in depression. Prog Neuropsychopharmacol Biol Psychiatry 35: 722-729.

28. Dagyt Ä- G, Crescente I, Postema F, Seguin L, Gabriel C, et al. (2011) Agomelatine reverses the decrease in hippocampal cell survival induced by chronic mild stress. Behav Brain Res 218: 121-128.

29. You Z, Luo C, Zhang W, Chen Y, He J, et al. (2011) Pro- and anti-inflammatory cytokines expression in rat's brain and spleen exposed to chronic mild stress: Involvement in depression. Behav Brain Res 225: 135-141.

30. Wollman I (2010) Role de l'audition dans la perception de l'espace. Thèse de doctorat. Paris. France: 139.

31. Prut L, Belzung C (2003) The open field as a paradigm to measure the effects of drugs on anxiety-like behaviors: a review. Eur J Pharmacol 463: 3-33.
32. Elizalde N, Gil-Bea FJ, Ramirez MJ, Aisa B, Lasheras B, et al. (2008) Longlasting behavioral effects and recognition memory deficit induced by chronic mild stress in mice : effect of antidepressant treatment. Psychopharmacology 199: 1-14.

33. Li S, Wang C, Wang W, Dong H, Hou P, et al. (2008) Chronic mild stress impairs cognition in mice: from brain homeostasis to behavior. Life Sci 82: 934 942.

34. Mineur YS, Belzung C, Crusio WE (2007) Functional implications of decreases in neurogenesis following chronic mild stress in mice. Neuroscience 150: 251 259.

35. Gomes KS, Nunes-De-Souza RL (2009) Implication of the 5-HT2A and 5-HT2C (but not $5 \mathrm{HT} 1 \mathrm{~A}$ ) receptors located within the peri aqueductal gray in the elevated plus-maze test-retest paradigm in mice. Prog in NeuroPsychopharmacol Biol Psychiatry 33: 1261-1269.

36. Mollace V, Nottet HS, Clayette P, Turco MC, Muscoli C, et al. (2001) Oxidative stress and neuroAIDS: triggers, modulators and novel antioxidants. Trends Neurosci 24: 411-416.

37. Power C, Gill MJ, Johnson RT (2002) Progress in clinical neurosciences: The neuropathogenesis of HIV infection: host-virus interaction and the impact of therapy. Can J Neurol Sci 29: 19-32.

38. Pomerantz RJ (2004) Effects of HIV-1 Vpr on neuroinvasion and neuropathogenesis. DNA Cell Biol 23: 227-238.

39. Wallace DR (2006) HIV neurotoxicity: potential therapeutic interventions. J Biomed Biotechnol 2006: 65741.

40. Bian Y, Pan Z, Hou Z, Huang C, Li W, et al. (2012) Learning, memory, and glial cell changes following recovery from chronic unpredictable stress. Brain Res Bull 88: 471-476.

41. Miller AH (2010) Depression and immunity: a role for $\mathrm{T}$ cells? Brain Behav Immun 24: 1-8.

42. Skurlova M, Stofkova A, Jurcovicova J (2011) Anxiety-like behavior in the elevated-plus maze tests and enhanced IL-1 $\hat{I}^{2}$, IL-6, NADPH oxidase-1, and iNOS mRNAs in the hippocampus during early stage of adjuvant arthritis in rats. Neurosci Lett 487: 250-254.

43. Song C (2002) The effect of thymectomy and IL-1 on memory: implications for the relationship between immunity and depression. Brain Behav Immun 16 557-568.

44. Diane A (2006) Stress, axe corticotrope et caractéristiques nutritionnelles et métaboliques. Thèse de Doctorat es Sciences. INA. Paris Grignon France.

45. Parent AJ, Beaudet N, Beaudry H, Bergeron J, Bérubé P, et al. (2012) Increased anxiety-like behaviors in rats experiencing chronic inflammatory pain. Behav Brain Res 229: 160-167.

46. Ishiyama N, Kitagawa M, Takahashi H, Kina T, Hirokawa K (1998) Expression of VCAM-1 in lymphocytes during the process of apoptosis. Pathobiology 66 274-283.

47. Hirokawa K, Sato K, Makinodan T (1982) Influence of age of thymic grafts on the differentiation of $\mathrm{T}$ cells in nude mice. Clin Immunol Immunopathol 24 251-262.

48. Arzt E, Buric R, Stelzer G, Stalla J Sauer J et al (1993) Interleukin involvement in anterior pituitary cell growth regulation: effects of IL-2 and IL-6. Endocrinology 132: 459-467.

49. Karanth S, Lyson K, McCann SM (1993) Role of nitric oxide in interleukin 2-induced corticotropin-releasing factor release from incubated hypothalami. Proc Natl Acad Sci U S A 90: 3383-3387.

50. Todd KG, Butterworth RF (1999) Early microglial response in experimental thiamine deficiency: an immunohistochemical analysis. Glia 25: 190-198.

51. Hallenbeck JM (2002) The many faces of tumor necrosis factor in stroke. Nat Med 8: $1363-1368$

52. Williams MA, Turchan J, Lu Y, Nath A, Drachman DB (2005) Protection of human cerebral neurons from neurodegenerative insults by gene delivery of soluble tumor necrosis factor p75 receptor. Exp Brain Res 165: 383-391.

53. Marchetti L, Klein M, Schlett K, Pfizenmaier K, Eisel UL (2004) Tumor necrosis factor (TNF)-mediated neuroprotection against glutamate-induced excitotoxicity is enhanced by $\mathrm{N}$-methyl-D-aspartate receptor activation. Essential role of a 
Citation: Frih H, Bensaci L, Djenidi R, Rachedi BA, Tahraoui A, et al. (2013) Freund's Complete Adjuvant (FCA) Could Reverse the Depressive-Like Symptoms Induced by Chronic Mild Stress (CMS) in Mice. J Neurol Neurophysiol 4: 143. doi:10.4172/2155-9562.1000143

Page 8 of 8

TNF receptor 2-mediated phosphatidylinositol 3-kinase-dependent NF-kappa B pathway. J Biol Chem 279:32869-32881.

54. Munhoz C, Madrigal JL, García-Bueno B, Pradillo JM, Moro MA, et al. (2004) TNF-alpha accounts for short-term persistence of oxidative status in rat brain after two weeks of repeated stress. Eur J Neurosci 20: 1125-1130.
55. Lucas SM, Rothwell NJ, Gibson RM (2006) The role of inflammation in CNS injury and disease. Br J Pharmacol 147: S232-S240.

56. Allan SM, Rothwell NJ (2003) Inflammation in central nervous system injury. Philos Trans R Soc Lond B Biol Sci 358: 1669-1677. 